\title{
Kinetic Studies of Heterogeneous Reactions of Polycyclic Aromatic Hydrocarbon Aerosols with $\mathrm{NO}_{3}$ Radicals
}

\author{
Changgeng Liu, Peng Zhang, Bo Yang, Youfeng Wang, and Jinian Shu* \\ Research Center for Eco-Environmental Sciences, Chinese Academy of Sciences, Beijing 100085, China
}

Supporting Information

ABSTRACT: Polycyclic aromatic hydrocarbons (PAHs) and their derivates are mutagenic and carcinogenic substances widely distributed in the atmospheric environment. In this study, effective rate constants for heterogeneous reactions of $\mathrm{NO}_{3}$ radicals with five 4-ring PAHs [benzo[a] anthracene $(\mathrm{BaA})$, chrysene $(\mathrm{Ch})$, pyrene (Py), 1-nitropyrene (1-NP), and 1-hydroxypyrene (1-OHP)] adsorbed on suspended azelaic acid particles are investigated by a mixed-phase relative rate method with gas-phase isoprene as the reference substance. The concentrations of suspended PAH particles and gas-phase isoprene are monitored concurrently by a real-time vacuum ultraviolet photoionization aerosol time-of-flight mass spectrometer (VUV-ATOFMS) and an online atmospheric gas analysis mass spectrometer, respectively. The obtained effective rate

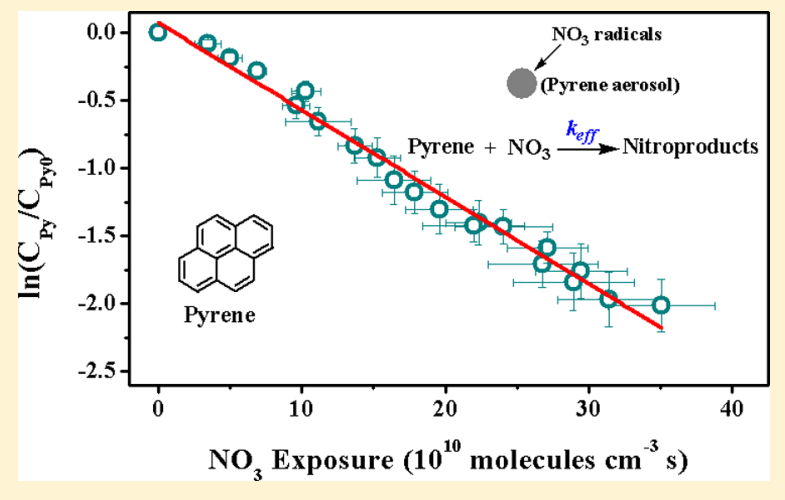
constants for the reactions of $\mathrm{BaA}, \mathrm{Ch}, \mathrm{Py}, 1-\mathrm{NP}$, and 1-OHP particles with $\mathrm{NO}_{3}$ radicals are $4.3 \times 10^{-12}, 4.0 \times 10^{-12}, 6.4 \times 10^{-12}, 1.3 \times 10^{-12}$, and $1.0 \times 10^{-11} \mathrm{~cm}^{3} \cdot \mathrm{molecule}^{-1} \cdot \mathrm{s}^{-1}$, respectively, and their corresponding atmospheric lifetimes range from several minutes to half an hour at the $\mathrm{NO}_{3}$ radical concentration of $5 \times 10^{8}$ molecules $\cdot \mathrm{cm}^{-3}$. In addition, the $\mathrm{NO}_{3}$ uptake coefficients on particulate PAHs are estimated according to the consumption of PAHs under the exposure of $\mathrm{NO}_{3}$ radicals. The experimental results of these heterogeneous reactions in the aerosol state provide supplementary knowledge for kinetic behaviors of airborne PAHs particles.

\section{INTRODUCTION}

Polycyclic aromatic hydrocarbons (PAHs) are ubiquitous pollutants in the atmospheric environment with mutagenic and carcinogenic properties. ${ }^{1,2}$ These compounds principally originate from incomplete combustion and are released into the atmosphere by sources such as vehicles, coal-fired power plants, and wood burning. ${ }^{3}$ The atmospheric concentrations of particulate PAHs are in the range of a few to several hundred nanograms per cubic meter for urban areas, ${ }^{3,4}$ and about $90 \%$ of PAHs emissions are anthropogenic. ${ }^{5}$ In the atmosphere, low molecular weight PAHs are mainly present in the gas phase, while PAHs with more than four rings are primarily found adsorbed on particulate matter, especially on particles with a diameter below $3 \mu \mathrm{m} .{ }^{6}$ After their emission into the atmosphere, PAHs can undergo photolysis or chemical transformation processes in both gas and particulate phases due to interactions with atmospheric trace gases. Heterogeneous reactions of particulate PAHs are an important degradation pathway, which frequently lead to the formation of some reaction products showing more toxicity than their parent chemicals, such as nitrated polycyclic aromatic hydrocarbons (NPAHs). ${ }^{1,2}$ Therefore, understanding the atmospheric lifetime and fate of $\mathrm{PAH}$ aerosols is very important for health risk assessments.

In order to document their lifetimes in the atmosphere, substantial efforts have been made on the homogeneous chemistry between PAHs and gas-phase oxidants since a few decades ago. ${ }^{7,8}$ However, the kinetics and mechanism of heterogeneous reaction can differ dramatically from those of homogeneous reaction. ${ }^{1,9}$ The previous studies revealed that heterogeneous reactions of adsorbed PAHs were much faster (by several orders of magnitude) than their corresponding gasphase reactions. ${ }^{8,10-12}$ Besides, PAHs with high molecular weights are mainly associated with particles in the atmosphere due to their low volatility. Thus, the heterogeneous reactions of these compounds may be the main degradation pathway in the atmosphere. ${ }^{10}$ In the past decade, kinetics of heterogeneous reactions between gas-phase oxidants $\left(\mathrm{NO}_{2}, \mathrm{O}_{3}\right.$, and $\mathrm{OH}$ radicals) and PAHs adsorbed on various carrier surfaces (soot, mineral particles, organic aerosols, etc.) have been studied intensively. ${ }^{8,10,11,13-26}$ Additionally, because $\mathrm{NO}_{3}$ radicals play an important role in the atmospheric chemistry at nighttime, heterogeneous reactions of surface-bound PAHs with $\mathrm{NO}_{3}$ radicals have been investigated by a few groups in recent years. $^{12,23,24,27,28}$ Shiraiwa et al. ${ }^{23}$ reported that the rate constants for surface layer reactions of $\mathrm{PAHs}$ with $\mathrm{NO}_{3}$ radicals were in the range from $10^{-15}$ to $10^{-12} \mathrm{~cm}^{2} \cdot \mathrm{s}^{-1}$. Kaiser et al. ${ }^{24}$

Received: April 9, 2012

Revised: June 28, 2012

Accepted: July 2, 2012

Published: July 2, 2012 
indicated that PAHs were degraded rapidly at nighttime due to gas-surface reactions with $\mathrm{NO}_{3}$ radicals. Besides, some studies on the uptake coefficients and reaction products of heterogeneous reactions between PAHs and $\mathrm{NO}_{3}$ radicals have been performed. ${ }^{12,24,27,28}$ However, to our knowledge, few reaction rate data for the reactions of suspended $\mathrm{PAH}$ particles with $\mathrm{NO}_{3}$ radicals have been determined.

In this study, effective rate constants for heterogeneous reactions of $\mathrm{NO}_{3}$ radicals with five 4-ring PAHs adsorbed on suspended azelaic acid particles are determined via a mixedphase relative rate approach. The five 4-ring PAHs used in the experiment are benzo[a] anthracene $(\mathrm{BaA})$, chrysene $(\mathrm{Ch})$, pyrene (Py), and two derivatives of Py [1-nitropyrene (1-NP) and 1-hydroxypyrene (1-OHP)]. All of them have been observed in the atmosphere., ${ }^{3,29-31}$ During the reaction process, the concentration changes of suspended $\mathrm{PAH}$ particles and gas-phase isoprene are measured synchronously by a realtime vacuum ultraviolet photoionization aerosol time-of-flight mass spectrometer (VUV-ATOFMS) and an online atmospheric gas analysis mass spectrometer, respectively.

\section{EXPERIMENTAL SECTION}

The experimental setup of the heterogeneous reaction between $\mathrm{PAH}$ aerosols and $\mathrm{NO}_{3}$ radicals has been described in detail elsewhere. $^{32}$ Briefly, it consists of an aerosol generator, a reaction chamber, and analytical instruments.

$\mathrm{PAH}$ aerosols are generated through homogeneous nucleation. The aerosol generator is an electric tube furnace equipped with two tandem quartz tubes $[50 \mathrm{~cm}$ (length) $\times 3 \mathrm{~cm}$ (inner diameter)], each with an independent temperature controller. Azelaic acid is used to produce nuclei in this study due to its limited reactivity toward $\mathrm{NO}_{3}$ radicals. Pure azelaic acid particles are exposed to $\mathrm{NO}_{3}$ radicals at a concentration of $\sim 5 \times 10^{9}$ molecules $\cdot \mathrm{cm}^{-3}$ for $10 \mathrm{~min}$, and no reaction product is observed with ATOFMS. Azelaic acid is placed in the first tube while the PAH sample in the second tube. $\mathrm{A} \mathrm{N}_{2}$ stream with a volumetric flow rate of $0.6 \mathrm{~L} \cdot \mathrm{min}^{-1}$ flows through the first tube, bringing the nuclei into the second tube. In the second tube, the azelaic acid nuclei are coated by the $\mathrm{PAH}$ sample. The size and concentration of particles are monitored by a scanning mobility particle sizer (SMPS), which is composed of a differential mobility analyzer (DMA, TSI 3081) and a condensation particle counter (CPC, TSI 3010). The measured mean diameters of $\mathrm{BaA}, \mathrm{Ch}, \mathrm{Py}, 1-\mathrm{NP}$, and 1OHP particles are $310,324,292,280$, and $285 \mathrm{~nm}$, respectively, and their corresponding mass concentrations are $274 \pm 17,424$ $\pm 38,211 \pm 15,421 \pm 33$, and $396 \pm 29 \mu \mathrm{g} \cdot \mathrm{m}^{-3}$. The geometric standard deviations of particles are 1.2-1.4. The thicknesses of the coatings are 33, 40, 34, 29, and $27 \mathrm{~nm}$ for $\mathrm{BaA}, \mathrm{Ch}, \mathrm{Py}, 1-\mathrm{NP}$, and 1-OHP, respectively, calculated according to the size distributions of particles before and after coating by the PAH sample.

The reaction chamber with a volume of $\sim 180 \mathrm{~L}$ consists of a thin-walled open head stainless steel drum and a thin Tedlar poly(vinyl fluoride) (PVF) film bag. A magnetic-driven fan is set at the bottom of the reaction chamber to ensure that the reactants could be mixed rapidly and sufficiently. The experiments are performed under atmospheric pressure at room temperature of $\sim 287 \mathrm{~K}$. The relative humidity in the chamber is roughly estimated to be $\sim 5 \%$ from the residual filtered air in the chamber. After the concentration of $\mathrm{PAH}$ particles within the reaction chamber reaches the desired value, isoprene is injected into the reaction chamber. The initial concentration of isoprene in the chamber is $\sim 1.5 \times 10^{14}$ molecules $\cdot \mathrm{cm}^{-3}$, measured with an atmospheric gas analysis mass spectrometer (QIC-20-HAL3F-RC, Hiden) via detection of the mass peak at $m / z 67\left(\mathrm{C}_{5} \mathrm{H}_{7}{ }^{+}\right)$. Then, a $\mathrm{N}_{2}$ stream with a volumetric flow rate of $0.6 \mathrm{~L} \cdot \mathrm{min}^{-1}$ passes through a flask containing $\mathrm{N}_{2} \mathrm{O}_{5}$ powder and introduces $\mathrm{N}_{2} \mathrm{O}_{5}$ vapor into the reaction chamber. $\mathrm{NO}_{3}$ radicals are generated by thermal decomposition of $\mathrm{N}_{2} \mathrm{O}_{5}$ at the room temperature of $\sim 287 \mathrm{~K}$. The concentrations of $\mathrm{NO}_{3}$ radicals employed in the experiment are (1.4-18) $\times 10^{9}$ molecules $\cdot \mathrm{cm}^{-3}$, estimated according to the loss rates of isoprene. The $400 \mathrm{~s}$ wall losses of PAHs and isoprene in the absence of oxidants are below 5\%, monitored with the VUV-ATOFMS and the atmospheric gas analysis mass spectrometer, respectively.

The concentrations of $\mathrm{PAH}$ aerosols are measured in real time with VUV-ATOFMS via detection of their molecular ion mass peaks. Detailed descriptions of VUV-ATOFMS have been presented elsewhere. ${ }^{32,33}$ Therefore, only a brief description of VUV-ATOFMS is presented here. It consists of three collimated chambers: a source chamber, a differential chamber, and a detection chamber. ${ }^{33}$ An $8 \mathrm{~mm}$ diameter copper rod coupled with a cartridge heater $(\sim 523 \mathrm{~K})$ placed in the detection chamber is used to vaporize the particles; the nascent organic vapor is photoionized with VUV light emitted from a VUV light lamp with a photon flux of $\sim 5 \times 10^{14}$ photons $\cdot \mathrm{s}^{-1}$ and a photon energy of $10 \mathrm{eV} .^{33}$ The pulsed electric field of the ion repeller runs at $15 \mathrm{kHz}$. Each time-of-flight mass spectrum takes $10 \mathrm{~s}$ of acquisition and $1 \mathrm{~s}$ of saving data files. The mass resolution of VUV-ATOFMS is $\sim 1000$ and the detection limit is $\sim 0.5 \mu \mathrm{g} \cdot \mathrm{m}^{-3}$ for PAHs.

Three duplicate experiments are performed for the heterogeneous reaction of each $\mathrm{PAH}$ sample. Before every single experiment, the reaction chamber is rinsed thoroughly with absolute ethyl alcohol and dried with hot air. During the experiment, the atmospheric gas analysis mass spectrometer and VUV-ATOFMS respectively monitor the concentrations of isoprene and $\mathrm{PAH}$ particles every $11 \mathrm{~s}$. The data are recorded continuously until the end of the reaction. Since the concentration of $\mathrm{PAH}$ particles is linear with respect to the signal intensity of the mass peak measured by VUVATOFMS $^{33}$ the decay rate of signal intensity is equal to the decay rate of $\mathrm{PAH}$ concentration. In addition, the reaction products are identified with an Agilent $6890 \mathrm{GC} / \mathrm{MS}$ and the analysis method has been described in detail elsewhere. ${ }^{28}$

The PAHs samples used in the experiment are listed in Table 1. Azelaic acid (Sinopharm Chemical Reagent Co., Ltd., 99\%), fuming nitric acid (Beijing Lisui Chemical Factory, 95\%), $\mathrm{P}_{2} \mathrm{O}_{5}$ (Sinopharm Chemical Reagent Co., Ltd., 98\%), absolute ethyl alcohol (Sinopharm Chemical Reagent Co., Ltd., 99.7\%), and dichloromethane (J. T. Baker Co., chromatographic grade) are used in the experiment. Nitrogen (99.99\%) is purchased from Beijing Huayuan Gas Chemical Industry Co. Ltd.

\section{RESULTS AND DISCUSSION}

The maximum average concentrations of $\mathrm{NO}_{2}$ and $\mathrm{N}_{2} \mathrm{O}_{5}$ in this work are estimated to be $3.0 \times 10^{13}$ and $2.8 \times 10^{15}$ molecules $\cdot \mathrm{cm}^{-3}$, respectively, according to the maximum loss of isoprene and the thermal decomposition rate of $\mathrm{N}_{2} \mathrm{O}_{5}$ at $\sim 287 \mathrm{~K}^{34}$ In order to evaluate the possible effects of the reactions between $\mathrm{PAH}$ aerosols and $\mathrm{NO}_{2}$ on the decays of PAHs in the experiment, $\mathrm{PAH}$ particulates exposed to $\mathrm{NO}_{2}$ with a concentration of $\sim 4.6 \times 10^{13}$ molecules $\cdot \mathrm{cm}^{-3}$ are investigated. The results show that there are no apparent 
Table 1. Polycyclic Aromatic Hydrocarbons Used in the Experiment

\begin{tabular}{|c|c|c|c|c|c|}
\hline Name & Formula & Structure & MW & Purity & Supplier \\
\hline $\mathrm{BaA}$ & $\mathrm{C}_{18} \mathrm{H}_{12}$ & & 228 & $98 \%$ & TIC-GR \\
\hline $\mathrm{Ch}$ & $\mathrm{C}_{18} \mathrm{H}_{12}$ & & 228 & $98 \%$ & Sigma-Aldrich \\
\hline Py & $\mathrm{C}_{16} \mathrm{H}_{10}$ & & 202 & $98 \%$ & Sigma-Aldrich \\
\hline $1-N P$ & $\mathrm{C}_{16} \mathrm{H}_{9} \mathrm{NO}_{2}$ & & 247 & $97 \%$ & Matrix Scientific \\
\hline 1-OHP & $\mathrm{C}_{16} \mathrm{H}_{10} \mathrm{O}$ & & 218 & $98 \%$ & Sigma-Aldrich \\
\hline
\end{tabular}

products produced after $\mathrm{PAH}$ particulates are exposed to $\mathrm{NO}_{2}$ for $400 \mathrm{~s}$. Besides, it was reported that the reactive uptake coefficients of $\mathrm{NO}_{3}$ radicals on $\mathrm{PAH}$ surfaces were 4 orders of magnitude higher than those of $\mathrm{NO}_{2}{ }^{12}$ Considering that the maximum acquisition time of the kinetic data in the experiment is less than $300 \mathrm{~s}$, the direct loss of PAH aerosols due to the reaction with $\mathrm{NO}_{2}$ is neglected in this study. Kamens et al. ${ }^{35}$ have reported that the heterogeneous rate constants for reactions of PAHs with $\mathrm{N}_{2} \mathrm{O}_{5}\left(\sim 2.5 \times 10^{14}\right.$ molecules $\left.\cdot \mathrm{cm}^{-3}\right)$ are on the order of $10^{-18} \mathrm{~cm}^{3} \cdot$ molecule ${ }^{-1} \cdot \mathrm{s}^{-1}$. These results suggest that $\mathrm{PAH}$ heterogeneous reactions with $\mathrm{N}_{2} \mathrm{O}_{5}$ to degrade particle-bound PAHs are not important. Besides, the reported reactive uptake coefficients of $\mathrm{N}_{2} \mathrm{O}_{5}$ on $\mathrm{PAH}$ surfaces were 4 orders of magnitude lower than those of $\mathrm{NO}_{3}$ radicals. ${ }^{12}$ Therefore, the effects of $\mathrm{N}_{2} \mathrm{O}_{5}$ on the loss of PAHs are also ignored in the experiment.

Reaction Products. The mononitro, dinitro, and polynitro products from successive nitro-substitution reactions of $\mathrm{PAH}$ particles are observed in real time with VUV-ATOFMS. 7Nitrobenzo $[a]$ anthracene, benzo $[a]$ anthracene-7,12-dione, 1nitropyrene, and 1,3-, 1,6-, and 1,8-dinitropyrene are identified as the main reaction products of $\mathrm{BaA}, \mathrm{Py}$, and $1-\mathrm{NP}$ by GC/MS analysis (Table $S 1$ in Supporting Information). Polynitro products of 1-OHP observed with VUV-ATOFMS are not identified successfully by GC/MS analysis. The failure may be due to the polarity and thermal instability of the reaction products. These experimental results are consistent with our previous studies. $^{28}$ TOF mass spectra of BaA, Py, 1-NP, and 1OHP particles and their products in the reactions with $\mathrm{NO}_{3}$ radicals are shown in Figures $S 1$ and $S 2$ in Supporting Information, which have been reported and discussed in detail in earlier studies. ${ }^{28}$ Figure 1a shows the TOF mass spectrum of $\mathrm{Ch}$ particles in the reaction chamber before exposure to $\mathrm{NO}_{3}$ radicals. The ion peak at $\mathrm{m} / z 228$ corresponds to the molecular ion peak of $\mathrm{Ch}$. The mass spectrum shown in Figure $1 \mathrm{~b}$ is acquired $200 \mathrm{~s}$ after the injection of $\mathrm{NO}_{3}$ radicals into the reaction chamber, and there are two new mass peaks appearing at $m / z 273$ and 318 , which are assigned as mononitrochrysene and dinitrochrysene, respectively, on the basis of the ratios of mass to charge $(\mathrm{m} / z)$. The mononitrochrysene is further identified as 6-nitrochrysene on the basis of GC/MS analysis, which has been observed in the atmospheric particulate matter. ${ }^{29}$ As reported in the literature, the reaction of $\mathrm{NO}_{3}$

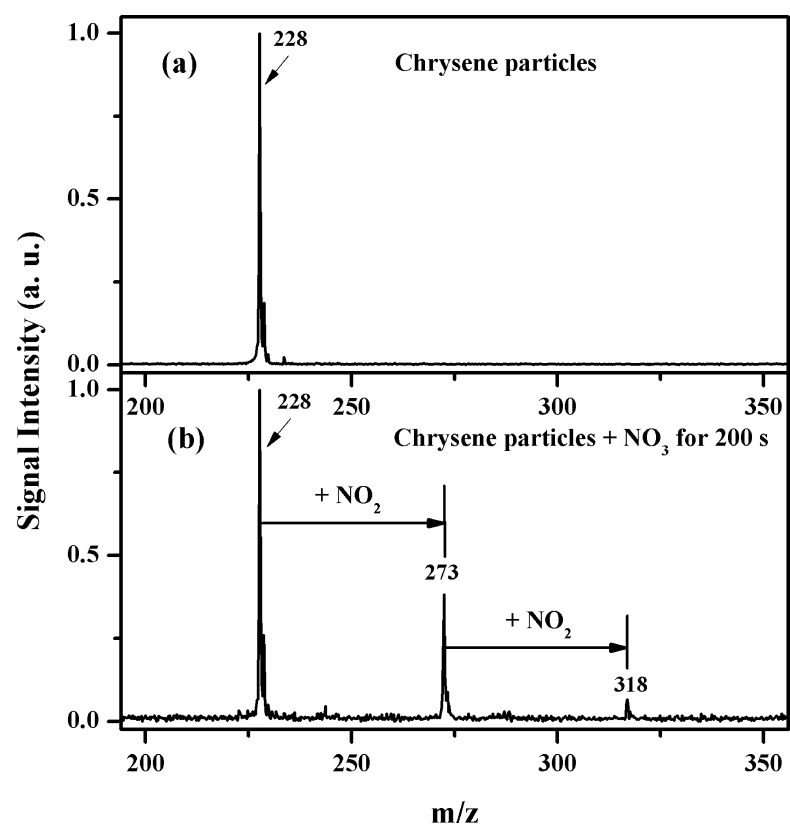

Figure 1. TOF mass spectra of (a) Ch particles and (b) their oxidation products after reaction with $\mathrm{NO}_{3}$ radicals. The mass spectrum shown in Figure $1 \mathrm{~b}$ is acquired $200 \mathrm{~s}$ after exposure to $\mathrm{NO}_{3}$ radicals. The acquisition time for each mass spectrum is $10 \mathrm{~s}$. The concentration of $\mathrm{NO}_{3}$ radicals exposed to $\mathrm{Ch}$ particles is approximately $4.0 \times 10^{9}$ molecules $\cdot \mathrm{cm}^{-3}$.

radicals with $\mathrm{PAH}$ begins with an initial addition of the $\mathrm{NO}_{3}$ radical to the aromatic rings to form a nitratocyclohexadienyltype radical, which then either decomposes back to reactants or reacts exclusively with $\mathrm{NO}_{2}$ to form NPAHs. ${ }^{36-38}$ The oxidation products observed in this study are mutagenic and carcinogenic and are recognized to be secondary air toxics. $^{1,2,19,39}$

Effective Rate Constants. According to the mixed-phase relative rate expression presented in the previous studies, the effective mixed-phase ratio of rate constants $\left(k_{\mathrm{PAH}} / k_{\mathrm{ref}}\right)_{\mathrm{eff}}^{\mathrm{m}}$ can be typically expressed as follows: ${ }^{40,41}$

$$
\ln \left(C_{\mathrm{PAH}} / C_{\mathrm{PAH} 0}\right)=\left(k_{\mathrm{PAH}} / k_{\text {ref }}\right)_{\text {eff }}^{\mathrm{m}} \ln \left(C_{\text {ref }} / C_{\text {refo }}\right)
$$

Here $C_{\mathrm{PAH}}$ and $C_{\text {ref }}$ are the real-time concentrations of particlebound PAH and gas-phase reference species, $C_{\mathrm{PAH} 0}$ and $C_{\text {ref0 }}$ are the initial concentrations of $\mathrm{PAH}$ particles and gas-phase reference species, $\left(k_{\mathrm{PAH}}\right)_{\mathrm{eff}}$ is the effective reaction rate constant of particulate $\mathrm{PAH}$, and $k_{\text {ref }}$ is the reaction rate constant of the gas-phase reference species. Isoprene served as the reference substance in the experiment, and the reaction rate constant of gas-phase isoprene with $\mathrm{NO}_{3}$ radicals adopted in this study is $7.0 \times 10^{-13} \mathrm{~cm}^{3} \cdot$ molecule ${ }^{-1} \cdot \mathrm{s}^{-1} \cdot{ }^{42}$ As the average $\mathrm{NO}_{3}$ radical exposure $\bar{C}_{\mathrm{NO}_{3}} t=-\ln \left(C_{\text {ref }} / C_{\text {refo }}\right) / k_{\text {ref }}{ }^{43}$ eq 1 can be transformed into eq $2:{ }^{44}$

$$
\ln \left(C_{\mathrm{PAH}} / C_{\mathrm{PAH} 0}\right)=-\left(k_{\mathrm{PAH}}\right)_{\mathrm{eff}} \bar{C}_{\mathrm{NO}_{3}} t
$$

Here $\bar{C}_{\mathrm{NO}_{3}}$ is the time-averaged concentration of $\mathrm{NO}_{3}$ radicals in the gas phase, and $t$ is the exposure time. By plotting $\ln$ $\left(C_{\mathrm{PAH}} / C_{\mathrm{PAH} 0}\right)$ versus $\bar{C}_{\mathrm{NO}_{3}} t$, the effective rate constant $\left(k_{\mathrm{PAH}}\right)_{\mathrm{eff}}$ can be obtained.

Figure 2 shows the plots of $\ln \left(C_{\mathrm{PAH}} / C_{\mathrm{PAH}}\right)$ versus $\mathrm{NO}_{3}$ radical exposure for $\mathrm{BaA}, \mathrm{Ch}, \mathrm{Py}, 1-\mathrm{NP}$, and 1-OHP particles. The wall losses $(<5 \%)$ of $\mathrm{PAH}$ particulates are ignored in the 


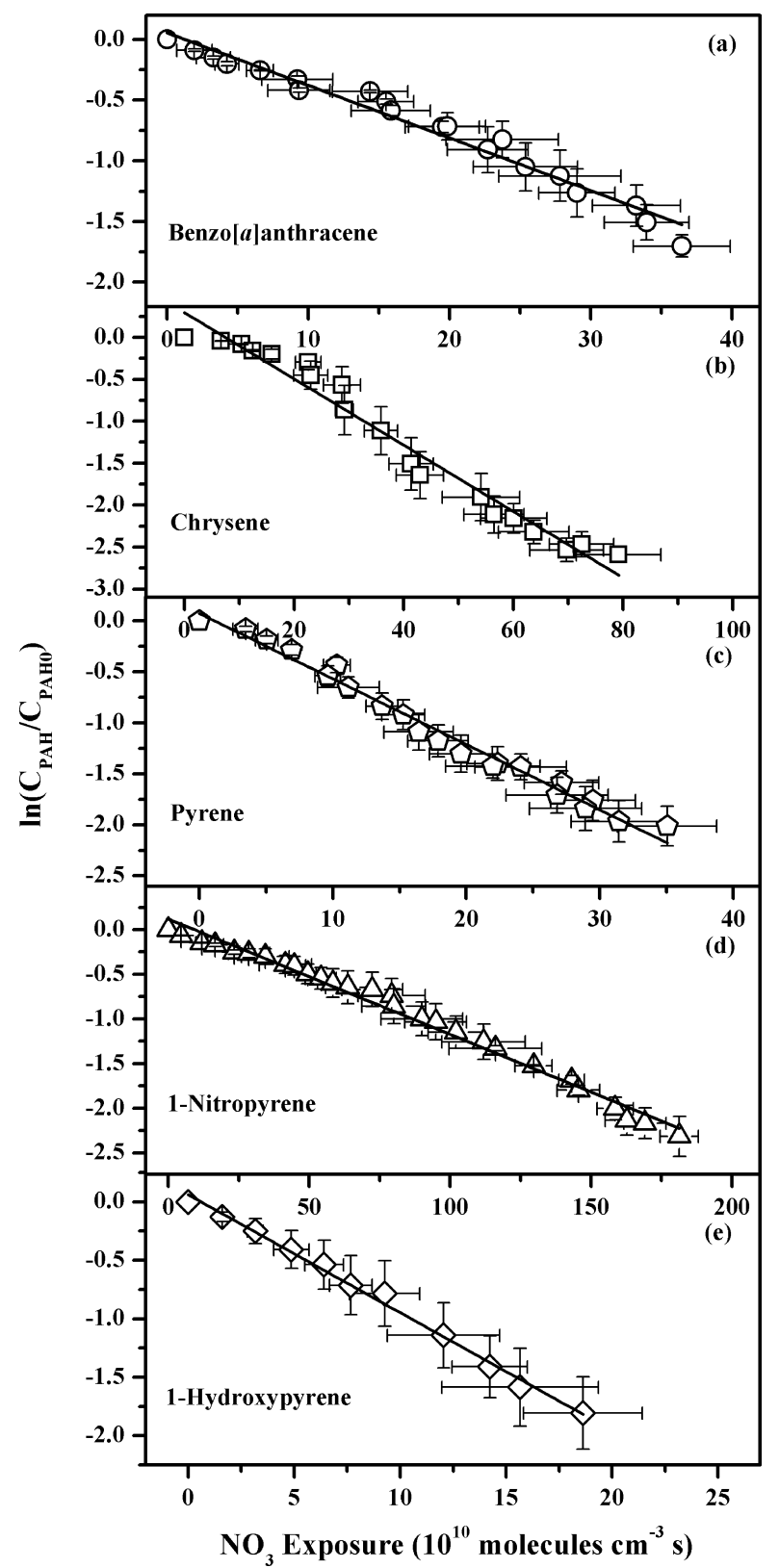

Figure 2. Plots of $\ln \left(C_{\mathrm{PAH}} / C_{\mathrm{PAH} 0}\right)$ versus $\mathrm{NO}_{3}$ radical exposure for (a) $\mathrm{BaA}$, (b) Ch, (c) Py, (d) 1-NP, and (e) 1-OHP particles. The average concentrations of $\mathrm{NO}_{3}$ radicals exposed to $\mathrm{BaA}, \mathrm{Ch}, \mathrm{Py}, 1-\mathrm{NP}$, and 1-OHP particles are approximately $1.7 \times 10^{9}, 4.0 \times 10^{9}, 1.6 \times 10^{9}$, $6.1 \times 10^{9}$, and $1.7 \times 10^{9}$ molecules $\cdot \mathrm{cm}^{-3}$, respectively. data processing. Error bars represent the standard deviation of three duplicate experiments. The five plots shown in Figure 2 are fitted well with linear least-squares fitting $\left(R^{2}>0.96\right)$. The obtained slopes of linear regressions correspond to the effective reaction rate constants $\left(k_{\text {eff }}\right)$ for $\mathrm{BaA}, \mathrm{Ch}, \mathrm{Py}, 1-\mathrm{NP}$, and 1-OHP particle reactions with $\mathrm{NO}_{3}$ radicals, which are $4.3 \times 10^{-12}, 4.0$ $\times 10^{-12}, 6.4 \times 10^{-12}, 1.3 \times 10^{-12}$, and $1.0 \times 10^{-11}$ $\mathrm{cm}^{3} \cdot$ molecule ${ }^{-1} \cdot \mathrm{s}^{-1}$, respectively (Table 2 ). The experimental results show that $1-\mathrm{OHP}$ is $\sim 8$ times more reactive than 1 -NP. The reactivities of $\mathrm{BaA}$ and $\mathrm{Ch}$ toward $\mathrm{NO}_{3}$ radicals are similar, both of which are $\sim 3$ times faster than that of 1-NP. The effective rate constant for Py particles is $\sim 1.5$ times larger than those of $\mathrm{BaA}$ and $\mathrm{Ch}$. Miet et al. ${ }^{14}$ reported that 1-OHP was more reactive than $\mathrm{Py}$ in the reaction with $\mathrm{O}_{3}$, whereas 1-NP was less reactive than Py. The reactivities of Py, 1-NP, and 1OHP toward $\mathrm{NO}_{3}$ radicals in this study are similar to their results. The heterogeneous reaction rates of $\mathrm{Py}$ and fluoranthene $(\mathrm{Fl})$ with $\mathrm{NO}_{3}$ radicals estimated by Gross and Bertram $^{12}$ were $8 \times 10^{-11}$ and $9 \times 10^{-12} \mathrm{~cm}^{3} \cdot$ molecule $^{-1} \cdot \mathrm{s}^{-1}$, respectively. The effective rate constants obtained in this study are basically consistent with their results.

$\mathrm{NO}_{3}$ Uptake Coefficients. The uptake coefficients $(\gamma)$ of $\mathrm{NO}_{3}$ radicals on $\mathrm{PAH}$ particles are calculated with the following equation, the detailed derivation of which is shown in Supporting Information:

$$
\gamma=\frac{\left(R_{\mathrm{p}}^{3}-R_{\mathrm{c}}^{3}\right) \rho_{\mathrm{PAH}} N_{\mathrm{A}} \eta_{\mathrm{PAH}}}{3 M_{\mathrm{PAH}} R_{\mathrm{p}} D_{\mathrm{NO}_{3}} \bar{C}_{\mathrm{NO}_{3}}{ }^{t}}
$$

Here $R_{\mathrm{p}}$ is the particle radius (centimeters), $R_{\mathrm{c}}$ is the radius of the inner core (centimeters), $\rho_{\mathrm{PAH}}$ is the PAH density $(1.2-1.4$ $\left.\mathrm{g} \cdot \mathrm{cm}^{-3}\right), N_{\mathrm{A}}$ is Avogadro's number, $\eta_{\mathrm{PAH}}$ is the ratio of consumption (0.8-0.9, depending on each PAH sample), $M_{\mathrm{PAH}}$ is the PAH molecular weight (grams per mole), $D_{\mathrm{NO}_{3}}$ is the diffusion coefficient of $\mathrm{NO}_{3}$ radicals $\left(\sim 0.12 \mathrm{~cm}^{2} \cdot \mathrm{s}^{-1}\right),{ }^{45}$ and $\overline{\mathrm{C}}_{\mathrm{NO}_{3}} t$ is the average $\mathrm{NO}_{3}$ exposure (molecules per cubic centimeter second).

According to eq 3, the uptake coefficients for $\mathrm{NO}_{3}$ radicals on $\mathrm{BaA}, \mathrm{Ch}, \mathrm{Py}, 1-\mathrm{NP}$, and 1-OHP particles are 2.4, 1.5, 3.1, 0.5 , and 4.8, respectively, which are much larger than the reported data. ${ }^{12,27}$ Lambe et al. $^{44}$ reported that evaporation followed by gas-phase oxidation was the main reason resulting in the uptake coefficients greater than unity observed in their experiment. In this experiment, the vapor pressures of the 4ring $\mathrm{PAHs}$ are less than $6 \times 10^{-4} \mathrm{~Pa}$ and their gas-phase reaction rates with $\mathrm{NO}_{3}$ radicals are on the order of $10^{-17}$ $10^{-16} \mathrm{~cm}^{3} \cdot$ molecule $^{-1} \cdot \mathrm{s}^{-1} \cdot 1,12,37,38$ Therefore, the influences of gas-phase reactions of the 4-ring PAHs on the uptake coefficients could be neglected. The diffusion coefficient

Table 2. Comparison of Rate Constants ${ }^{a}$ for Heterogeneous Reactions between Particulate PAHs and Different Atmospheric Oxidants

\begin{tabular}{|c|c|c|c|c|c|c|c|}
\hline \multirow[b]{2}{*}{ compd } & \multicolumn{2}{|c|}{$\mathrm{NO}_{2}$} & \multicolumn{2}{|c|}{$\mathrm{O}_{3}$} & \multicolumn{2}{|c|}{$\mathrm{OH}$ radicals } & \multirow{2}{*}{$\frac{\mathrm{NO}_{3} \text { radicals }}{{\text { azelaic } \text { acid }^{e}}^{e}}$} \\
\hline & graphite $^{b}$ & silica & graphite $^{c}$ & silica & graphite compds & SRM $1650 \mathrm{a}^{d}$ & \\
\hline $\mathrm{BaA}$ & $3.2 \times 10^{-17}$ & $6.7 \times 10^{-18 f}$ & $2.8 \times 10^{-17}$ & $8.7 \times 10^{-17 c}$ & $5.6 \times 10^{-12}$ & $3.2 \times 10^{-13}$ & $4.3 \times 10^{-12}$ \\
\hline $\mathrm{Ch}$ & $3.7 \times 10^{-17}$ & $6.0 \times 10^{-19 f}$ & $1.5 \times 10^{-17}$ & $3.1 \times 10^{-17 c}$ & $5.0 \times 10^{-12}$ & $4.4 \times 10^{-13}$ & $4.0 \times 10^{-12}$ \\
\hline Py & $5.1 \times 10^{-17}$ & $2.0 \times 10^{-17 f}$ & $2.5 \times 10^{-17}$ & $5.9 \times 10^{-17 c}$ & $3.1 \times 10^{-12}$ & $4.1 \times 10^{-13}$ & $6.4 \times 10^{-12}$ \\
\hline $1-\mathrm{NP}$ & & $6.2 \times 10^{-18 g}$ & & $2.2 \times 10^{-17 h}$ & & & $1.3 \times 10^{-12}$ \\
\hline 1-OHP & & & & $7.7 \times 10^{-16 h}$ & & & $1.0 \times 10^{-11}$ \\
\hline
\end{tabular}

${ }^{a}$ In units of cubic centimeters per molecule per second. ${ }^{b}$ Data derived from Esteve et al. ${ }^{17}{ }^{c}$ Data derived from Perraudin et al. ${ }^{8}{ }^{d}$ Data derived from Esteve et al. ${ }^{18} e$ This work. ${ }^{f}$ Data derived from Perraudin et al. ${ }^{20} .{ }^{g}$ Data derived from Miet et al. ${ }^{19}{ }^{h}$ Data derived from Miet et al. ${ }^{14}$ 
$\left(\sim 0.12 \mathrm{~cm}^{2} \cdot \mathrm{s}^{-1}\right)$ applied in the calculation above is the value used to describe natural diffusion resulting from the gradient in the concentration. When it is considered that $\mathrm{NO}_{3}$ radicals in the reaction chamber are forcedly diffused with a mixing fan, the diffusion coefficient under this circumstance should be much greater than that of natural diffusion. By use of the reported $\mathrm{NO}_{3}$ uptake coefficients on PAHs surfaces, ${ }^{12,27}$ a derived diffusion coefficient of $\sim 1.0 \mathrm{~cm}^{2} \cdot \mathrm{s}^{-1}$ is obtained for $\mathrm{NO}_{3}$ radicals under the experimental condition. Calculated with this diffusion coefficient, the corresponding uptake coefficients of $\mathrm{NO}_{3}$ radicals on $\mathrm{BaA}, \mathrm{Ch}, \mathrm{Py}, 1-\mathrm{NP}$, and 1-OHP particles are $0.29,0.18,0.37,0.06$, and 0.57 , respectively. We speculate that the corrected values are more reasonable.

Atmospheric Implications. Heterogeneous reactions of $\mathrm{NO}_{2}$ with PAHs adsorbed on various carrier surfaces have been performed intensively, and the rate constants for heterogeneous reactions of $\mathrm{NO}_{2}$ with $\mathrm{PAHs}$ are in the range $10^{-19}-10^{-17}$ $\mathrm{cm}^{3} \cdot$ molecule $\mathrm{e}^{-1} \cdot \mathrm{s}^{-1}$ (Table 2). ${ }^{17-21}$ The results obtained in this study show that the effective reaction rate constants of PAHs with $\mathrm{NO}_{3}$ radicals are about 5-7 orders of magnitude faster than those of adsorbed PAHs oxidized by $\mathrm{NO}_{2}$. Heterogeneous reactions of $\mathrm{O}_{3}$ with particulate $\mathrm{PAHs}$ also attracted much attention, and the rate constants for heterogeneous reactions of PAHs with $\mathrm{O}_{3}$ range from $10^{-18}$ to $10^{-16} \mathrm{~cm}^{3} \cdot$ molecule ${ }^{-1} \cdot \mathrm{s}^{-1}$ (Table 2) ${ }^{8,10,13-15}$ Thus, the obtained reaction rate constants of PAHs aerosols with $\mathrm{NO}_{3}$ radicals are about 4-6 orders of magnitude faster than those of adsorbed PAHs oxidized by $\mathrm{O}_{3}$. Shiraiwa et al. $^{23}$ reported that the surface layer reactions of PAHs with $\mathrm{NO}_{3}$ radicals were much faster (by 2-6 orders of magnitude) than those of $\mathrm{PAHs}$ with $\mathrm{NO}_{2}$ and $\mathrm{O}_{3}$. The results obtained in the experiment are consistent with those presented by Shiraiwa et al. ${ }^{23}$

In addition, the estimated rate constants of adsorbed PAHs with $\mathrm{OH}$ radicals range from $10^{-13}$ to $10^{-12} \mathrm{~cm}^{3} \cdot$ molecule ${ }^{-1} \cdot \mathrm{s}^{-1}$ (Table 2), ${ }^{17,18,22}$ which are close to the effective reaction rate constants for PAHs in the reactions with $\mathrm{NO}_{3}$ radicals obtained in this study. However, compared with $\mathrm{NO}_{3}$ radicals, the effect of $\mathrm{OH}$ radicals on the degradation of atmospheric particlebound PAHs may not be remarkable due to its lower concentration in the atmosphere. ${ }^{24}$ Recently, Kaiser et al. ${ }^{24}$ reported that $\mathrm{PAH}$ half-lives at nighttime were on the order of seconds due to rapid oxidation by gas-surface reactions with $\mathrm{NO}_{3}$ radicals, while half-lives of $\mathrm{PAH}$ aerosols at daytime were longer (on the order of minutes). The reported reaction rates of the homogeneous reactions between gas-phase 4-ring PAHs and $\mathrm{NO}_{3}$ radicals were on the order of $10^{-17}-10^{-16}$ $\mathrm{cm}^{3} \cdot$ molecule ${ }^{-1} \cdot \mathrm{s}^{-1} \cdot 1,37,38$ According to the effective rate constants obtained in this work and previous data, ${ }^{12}$ the gasphase reaction rates of $\mathrm{PAHs}$ with $\mathrm{NO}_{3}$ radicals are about 4-5 orders of magnitude slower than the heterogeneous reaction rates. Thereby, under typical atmospheric conditions at nighttime, $\mathrm{NO}_{3}$ radicals could be the most important oxidant for the degradation of atmospheric PAHs.

The concentrations of $\mathrm{NO}_{3}$ radicals employed in the experiment are close to the atmospheric concentration of $\mathrm{NO}_{3}$ radicals at nighttime. ${ }^{37}$ Therefore, the kinetic data obtained with eq 2 can be directly used to estimate the atmospheric lifetime of $\mathrm{PAH}$ aerosols. The corresponding lifetimes of $\mathrm{BaA}, \mathrm{Ch}, \mathrm{Py}, 1-\mathrm{NP}$, and 1-OHP are 7.8, 8.3, 5.2, 25.6, and $3.3 \mathrm{~min}$, respectively, calculated from a $\mathrm{NO}_{3}$ radical concentration of $5 \times 10^{8}$ molecules $\cdot \mathrm{cm}^{-3}$ in the lower troposphere at nighttime. ${ }^{37}$ To our knowledge, 1-OHP is rarely observed in the atmosphere, ${ }^{30}$ while the other four PAHs are reported in many field studies. ${ }^{3,4,29,31}$ These observations may partly reflect the lifetimes of these five PAHs. Under real atmospheric conditions, the phase and morphology of atmospheric particles may be quite complex, and those PAHs distributed in the particle bulk may not be accessible for oxidation by $\mathrm{NO}_{3}$ radicals (or other gas-phase oxidants). In addition, other factors such as atmospheric relative humidity, ${ }^{24}$ particle sizes, ${ }^{41}$ and concentrations of particulate reactants and gas-phase oxidants ${ }^{46}$ can affect heterogeneous reaction. As a result, the lifetimes of atmospheric PAHs aerosols may vary under different circumstances.

\section{ASSOCIATED CONTENT}

\section{S Supporting Information}

Additional text, one table, and two figures with information on reaction products, TOF mass spectra, and uptake calculations. This material is available free of charge via the Internet at http://pubs.acs.org/.

\section{AUTHOR INFORMATION}

\section{Corresponding Author}

*Tel: +86 10 62849508; fax: +86 10 62923563; e-mail: jshu@ rcees.ac.cn.

\section{Notes}

The authors declare no competing financial interest.

\section{ACKNOWLEDGMENTS}

This research was funded by Creative Research Groups of China (Grant 50921064) and National Natural Science Foundation of China (Grant 21077115).

\section{REFERENCES}

(1) Finlayson-Pitts, B. J.; Pitts, J. N. Chemistry of the Upper and Lower Atmosphere; Academic Press: San Diego, CA, 2000.

(2) Yaffe, D.; Cohen, Y.; Arey, J.; Grosovsky, A. J. Multimedia analysis of PAHs and nitro-PAH daughter products in the Los Angeles basin. Risk Anal. 2001, 21 (2), 275-294.

(3) Marr, L. C.; Dzepina, K.; Jimenez, J. L.; Reisen, F.; Bethel, H. L.; Arey, J.; Gaffney, J. S.; Marley, N. A.; Molina, L. T.; Molina, M. J. Sources and transformations of particle-bound polycyclic aromatic hydrocarbons in Mexico City. Atmos. Chem. Phys. 2006, 6, 1733-1745.

(4) Reisen, F.; Arey, J. Atmospheric reactions influence seasonal PAH and nitro-PAH concentrations in the Los Angeles basin. Environ. Sci. Technol. 2005, 39 (1), 64-73.

(5) Calvert, J. G.; Atkinson, R.; Becker, K. H.; Kamens, R. M.; Seinfeld, J. H.; Wallington, T. J.; Yarwood, G. The Mechanisms of Atmospheric Oxidation of Aromatic Hydrocarbons; Oxford University Press: Oxford, U.K., 2002.

(6) Pierce, R. C.; Katz, M. Dependency of polynuclear aromatic hydrocarbon content on size distribution of atmospheric aerosols. Environ. Sci. Technol. 1975, 9 (4), 347-353.

(7) Atkinson, R.; Baulch, D. L.; Cox, R. A.; Hampson, R. F.; Kerr, J. A.; Rossi, M. J.; Troe, J. Evaluated kinetic and photochemical data for atmospheric chemistry, organic species: Supplement VII. J. Phys. Chem. Ref. Data 1999, 28 (2), 191-393.

(8) Perraudin, E.; Budzinski, H.; Villenave, E. Kinetic study of the reactions of ozone with polycyclic aromatic hydrocarbons adsorbed on atmospheric model particles. J. Atmos. Chem. 2007, 56 (1), 57-82.

(9) Mmereki, B. T.; Donaldson, D. J.; Gilman, J. B.; Eliason, T. L.; Vaida, V. Kinetics and products of the reaction of gas-phase ozone with anthracene adsorbed at the air-aqueous interface. Atmos. Environ. 2004, 38 (36), 6091-6103.

(10) Kahan, T. F.; Kwamena, N. O. A.; Donaldson, D. J. Heterogeneous ozonation kinetics of polycyclic aromatic hydrocarbons on organic films. Atmos. Environ. 2006, 40 (19), 3448-3459. 
(11) Mmereki, B. T.; Donaldson, D. J. Direct observation of the kinetics of an atmospherically important reaction at the air-aqueous interface. J. Phys. Chem. A 2003, 107 (50), 11038-11042.

(12) Gross, S.; Bertram, A. K. Reactive uptake of $\mathrm{NO}_{3}, \mathrm{~N}_{2} \mathrm{O}_{5}, \mathrm{NO}_{2}$, $\mathrm{HNO}_{3}$, and $\mathrm{O}_{3}$ on three types of polycyclic aromatic hydrocarbon surfaces. J. Phys. Chem. A 2008, 112 (14), 3104-3113.

(13) Styler, S. A.; Loiseaux, M. E.; Donaldson, D. J. Substrate effects in the photoenhanced ozonation of pyrene. Atmos. Chem. Phys. 2011, 11 (3), 1243-1253.

(14) Miet, K.; Le Menach, K.; Flaud, P. M.; Budzinski, H.; Villenave, E. Heterogeneous reactions of ozone with pyrene, 1-hydroxypyrene and 1-nitropyrene adsorbed on particles. Atmos. Environ. 2009, 43 (24), 3699-3707.

(15) Kwamena, N. O. A.; Staikova, M. G.; Donaldson, D. J.; George, I. J.; Abbatt, J. P. D. Role of the aerosol substrate in the heterogeneous ozonation reactions of surface-bound PAHs. J. Phys. Chem. A 2007, 111 (43), 11050-11058.

(16) Kwamena, N. O. A.; Thornton, J. A.; Abbatt, J. P. D. Kinetics of surface-bound benzo[a]pyrene and ozone on solid organic and salt aerosols. J. Phys. Chem. A 2004, 108 (52), 11626-11634.

(17) Esteve, W.; Budzinski, H.; Villenave, E. Relative rate constants for the heterogeneous reactions of $\mathrm{OH}, \mathrm{NO}_{2}$ and $\mathrm{NO}$ radicals with polycyclic aromatic hydrocarbons adsorbed on carbonaceous particles. Part 1: PAHs adsorbed on 1-2 $\mu \mathrm{m}$ calibrated graphite particles. Atmos. Environ. 2004, 38 (35), 6063-6072.

(18) Esteve, W.; Budzinski, H.; Villenave, E. Relative rate constants for the heterogeneous reactions of $\mathrm{NO}_{2}$ and $\mathrm{OH}$ radicals with polycyclic aromatic hydrocarbons adsorbed on carbonaceous particles. Part 2: PAHs adsorbed on diesel particulate exhaust SRM 1650a. Atmos. Environ. 2006, 40 (2), 201-211.

(19) Miet, K.; Le Menach, K.; Flaud, P. M.; Budzinski, H.; Villenave, E. Heterogeneous reactivity of pyrene and 1-nitropyrene with $\mathrm{NO}_{2}$ : Kinetics, product yields and mechanism. Atmos. Environ. 2009, 43 (4), 837-843.

(20) Perraudin, E.; Budzinski, H.; Villenave, E. Kinetic study of the reactions of $\mathrm{NO}_{2}$ with polycyclic aromatic hydrocarbons adsorbed on silica particles. Atmos. Environ. 2005, 39 (35), 6557-6567.

(21) Nguyen, M. L.; Bedjanian, Y.; Guilloteau, A. Kinetics of the reactions of soot surface-bound polycyclic aromatic hydrocarbons with $\mathrm{NO}_{2}$. J. Atmos. Chem. 2009, 62 (2), 139-150.

(22) Bedjanian, Y.; Nguyen, M. L.; Le Bras, G. Kinetics of the reactions of soot surface-bound polycyclic aromatic hydrocarbons with the $\mathrm{OH}$ radicals. Atmos. Environ. 2010, 44 (14), 1754-1760.

(23) Shiraiwa, M.; Garland, R. M.; Poeschl, U. Kinetic double-layer model of aerosol surface chemistry and gas-particle interactions (K2SURF): Degradation of polycyclic aromatic hydrocarbons exposed to $\mathrm{O}_{3}, \mathrm{NO}_{2}, \mathrm{H}_{2} \mathrm{O}, \mathrm{OH}$ and $\mathrm{NO}_{3}$. Atmos. Chem. Phys. 2009, 9 (24), 95719586

(24) Kaiser, J. C.; Riemer, N.; Knopf, D. A. Detailed heterogeneous oxidation of soot surfaces in a particle-resolved aerosol model. Atmos. Chem. Phys. 2011, 11 (9), 4505-4520.

(25) Miet, K.; Budzinski, H.; Villenave, E. Heterogeneous reactions of $\mathrm{OH}$ radicals with particulate-pyrene and 1-nitropyrene of atmospheric interest. Polycyclic Aromat. Compd. 2009, 29 (5), 267281.

(26) Bertram, A. K.; Ivanov, A. V.; Hunter, M.; Molina, L. T.; Molina, M. J. The reaction probability of $\mathrm{OH}$ on organic surfaces of tropospheric interest. J. Phys. Chem. A 2001, 105 (41), 9415-9421.

(27) Mak, J.; Gross, S.; Bertram, A. K. Uptake of $\mathrm{NO}_{3}$ on soot and pyrene surfaces. Geophys. Res. Lett. 2007, 34, No. L10804, DOI: $10.1029 / 2007$ GL029756

(28) Zhang, Y.; Yang, B.; Gan, J.; Liu, C. G.; Shu, X.; Shu, J. N. Nitration of particle-associated PAHs and their derivatives (nitro-, oxy-, and hydroxy-PAHs) with $\mathrm{NO}_{3}$ radicals. Atmos. Environ. 2011, 45 (15), 2515-2521.

(29) Bamford, H. A.; Baker, J. E. Nitro-polycyclic aromatic hydrocarbon concentrations and sources in urban and suburban atmospheres of the Mid-Atlantic region. Atmos. Environ. 2003, 37 (15), 2077-2091.
(30) Kishikawa, N.; Morita, S.; Wada, M.; Ohba, Y.; Nakashima, K.; Kuroda, N. Determination of hydroxylated polycyclic aromatic hydrocarbons in airborne particulates by high-performance liquid chromatography with fluorescence detection. Anal. Sci. 2004, 20 (1), 129-132.

(31) Kavouras, I. G.; Koutrakis, P.; Tsapakis, M.; Lagoudaki, E.; Stephanou, E. G.; Von Baer, D.; Oyola, P. Source apportionment of urban particulate aliphatic and polynuclear aromatic hydrocarbons (PAHs) using multivariate methods. Environ. Sci. Technol. 2001, 35 (11), 2288-2294.

(32) Zhang, Y.; Yang, B.; Meng, J. W.; Gao, S. K.; Dong, X. Y.; Shu, J. $\mathrm{N}$. Homogeneous and heterogeneous reactions of phenanthrene with ozone. Atmos. Environ. 2010, 44 (5), 697-702.

(33) Shu, J. N.; Gao, S. K.; Li, Y. A VUV photoionization aerosol time-of-flight mass spectrometer with a RF-powered VUV lamp for laboratory-based organic aerosol measurements. Aerosol Sci. Technol. 2008, 42 (2), 110-113.

(34) Ide, T.; Nakayama, T.; Takahashi, K.; Matsumi, Y. Thermal decomposition rate of $\mathrm{N}_{2} \mathrm{O}_{5}$ measured by cavity ring-down spectroscopy. Int. J. Chem. Kinet. 2008, 40 (10), 679-684.

(35) Kamens, R. M.; Guo, J.; Guo, Z.; McDow, S. R. Polynuclear aromatic hydrocarbon degradation by heterogeneous reactions with $\mathrm{N}_{2} \mathrm{O}_{5}$ on atmospheric particles. Atmos. Environ., Part A 1990, 24 (5), $1161-1173$.

(36) Atkinson, R.; Tuazon, E. C.; Arey, J. Reactions of naphthalene in $\mathrm{N}_{2} \mathrm{O}_{5}-\mathrm{NO}_{3}-\mathrm{NO}_{2}$-air mixtures. Int. J. Chem. Kinet. 1990, 22 (10), 10711082 .

(37) Atkinson, R. Kinetics and mechanisms of the gas-phase reactions of the $\mathrm{NO}_{3}$ radical with organic compounds. J. Phys. Chem. Ref. Data 1991, 20 (3), 459-507.

(38) Atkinson, R.; Arey, J.; Zielinska, B.; Aschmann, S. M. Kinetics and nitro-products of the gas-phase $\mathrm{OH}$ and $\mathrm{NO}_{3}$ radical-initiated reactions of naphthalene- $d_{8}$, fluoranthene- $d_{10}$, and pyrene. Int. J. Chem. Kinet. 1990, 22 (9), 999-1014.

(39) Salmeen, I. T.; Pero, A. M.; Zator, R.; Schuetzle, D.; Riley, T. L. Ames assay chromatograms and the identification of mutagens in diesel particle extracts. Environ. Sci. Technol. 1984, 18 (5), 375-382.

(40) Donahue, N. M.; Robinson, A. L.; Hartz, K. E. H.; Sage, A. M.; Weitkamp, E. A. Competitive oxidation in atmospheric aerosols: The case for relative kinetics. Geophys. Res. Lett. 2005, 32, No. L16805, DOI: $10.1029 / 2005$ GL022893.

(41) Huff Hartz, K. E.; Weitkamp, E. A.; Sage, A. M.; Donahue, N. M.; Robinson, A. L. Laboratory measurements of the oxidation kinetics of organic aerosol mixtures using a relative rate constants approach. J. Geophys. Res. 2007, 112, No. D04204, DOI: 10.1029/ 2006JD007526.

(42) http://www.iupac-kinetic.ch.cam.ac.uk/

(43) Smith, J. D.; Kroll, J. H.; Cappa, C. D.; Che, D. L.; Liu, C. L.; Ahmed, M.; Leone, S. R.; Worsnop, D. R.; Wilson, K. R. The heterogeneous reaction of hydroxyl radicals with sub-micron squalane particles: a model system for understanding the oxidative aging of ambient aerosols. Atmos. Chem. Phys. 2009, 9 (9), 3209-3222.

(44) Lambe, A. T.; Miracolo, M. A.; Hennigan, C. J.; Robinson, A. L.; Donahue, N. M. Effective rate constants and uptake coefficients for the reactions of organic molecular markers (n-alkanes, hopanes, and steranes) in motor oil and diesel primary organic aerosols with hydroxyl radicals. Environ. Sci. Technol. 2009, 43 (23), 8794-8800.

(45) Rudick, Y.; Talukdar, R. K.; Imamura, T.; Fox, R. W.; Ravishankara, A. R. Uptake of $\mathrm{NO}_{3}$ on KI solutions: Rate coefficient for the $\mathrm{NO}_{3}+\mathrm{I}^{-}$reaction and gas-phase diffusion coefficients for $\mathrm{NO}_{3}$. Chem. Phys. Lett. 1996, 261 (4-5), 467-473.

(46) Ammann, M.; Pöschl, U.; Rudich, Y. Effects of reversible adsorption and Langmuir-Hinshelwood surface reactions on gas uptake by atmospheric particles. Phys. Chem. Chem. Phys. 2003, 5 (2), $351-356$. 